\title{
Does Non-Placement of a Drain in Breast Surgery Increase the Rate of Complications and Revisions?
}

\author{
Erhöht der Verzicht auf die Drainage bei Brustoperationen wegen eines \\ Karzinoms die Rate an Komplikationen und Revisionsoperationen?
}

Authors

Affiliations
F. K. Ebner ${ }^{1}$, T. W. P. FriedI ${ }^{1}$, N. deGregorio ${ }^{1}$, A. Reich ${ }^{1}$, W. Janni ${ }^{1}$, A. Rempen ${ }^{2}$

${ }^{1}$ Frauenklinik, Universitätsklinik, Ulm

2 Frauenklinik, Diakonieklinikum, Schwäbisch Hall

\section{Key words \\ - breast cancer \\ - breast \\ - breast malignancy \\ - complication \\ - drainage \\ - seroma \\ Schlüsselwörter \\ - Mammakarzinom \\ - Mamma \\ - Mammamalignom \\ - Komplikation \\ - Drainage \\ - Serom}

Deutschsprachige Zusatzinformationen online abrufbar unter: www.thieme-connect.de/ ejournals/toc/gebfra

received 28.10.2012 revised $\quad 19.8 .2013$ accepted 20.8.2013

Bibliography

DOI http://dx.doi.org/ 10.1055/s-0033-1351071

Geburtsh Frauenheilk 2013; 73 : 1128-1134 @ Georg Thieme Verlag KG Stuttgart · New York . ISSN 0016-5751

Correspondence

Dr. Florian K. Ebner, MD

Universitätsklinik

Frauenklinik

Prittwitzstraße 43

89075 Ulm

dr.ebner@web.de

\section{Abstract \\ $\nabla$}

Purpose: Although surgical therapy for breast cancer has become less radical, intrasurgical placement of drains and the use of compression bandages is still standard practice. However, evidence for the clinical benefit of wound drains is controversial, and use of drains is associated with increased pain and longer hospital stays. This raises the question whether, given the latest surgical techniques, wound drainage is still medically necessary.

Material and Method: A retrospective analysis was done of patients with breast cancer treated surgically between January 2009 and April 2012 in the Breast Centre Hohenlohe $(n=573)$. Complication rates and revision following surgery with and without placement of wound drains were compared for patients who had breast-conserving surgery $(n=425)$ and patients who underwent mastectomy ( $\mathrm{n}=148$ ).

Results: The baseline characteristics (age, number of resected lymph nodes, numbers of patients who had sentinel lymph node resection, tumour characteristics, receptor status and affected side) were comparable for the investigated patient groups. The overall rate of complications was $4 \%$. There was no significant difference with regard to complication rates after surgery with and without placement of wound drains between the group of patients with breast-conserving surgery and the group of patients with mastectomy ( $p=0.68$ and $\mathrm{p}=0.54$, respectively).

Conclusion: Our data indicate that nonplacement of a wound drain does not influence complication or revision rates after breast-conserving surgery or mastectomy.

\section{Zusammenfassung \\ $\nabla$}

Problem: Trotz der verringerten Radikalität der operativen Therapie des Mammakarzinoms werden häufig routinemäßig Redon-Drainagen angelegt. Der medizinische Nutzen von Drainage ist allerdings nicht unumstritten. Drainageneinlagen sind mit vermehrten Schmerzen und einer Verlängerung des stationären Aufenthalts verbunden. Somit stellt sich die Frage, ob eine RedonDrainage in Anbetracht der aktuellen Operationstechniken heute noch medizinisch notwendig ist. Material und Methode: In einer retrospektiven Analyse der im Zeitraum Januar 2009 - April 2012 operativ behandelten Mammakarzinompatientinnen des Brustzentrums Hohenlohe $(n=573)$ wurden Komplikations- und Revisionsraten zwischen Operationen mit und ohne Drainageneinlage sowohl für Patientinnen mit brusterhaltender Operation $(n=425)$ als auch für Patientinnen mit Mastektomie $(n=148)$ verglichen.

Ergebnisse: Die untersuchten Patientinnengruppen waren in Bezug auf Alter, entfernte Lymphknoten, Häufigkeit der Wächterlymphknotenentfernung, Tumoreigenschaften, Rezeptorstatus und Seitenverteilung vergleichbar. Die Komplikationsrate für das Gesamtkollektiv betrug $4 \%$. Weder für die Gruppe der Patientinnen mit brusterhaltender Operation noch für die Gruppe der Patientinnen mit Mastektomie gab es einen signifikanten Unterschied in der Häufigkeit des Auftretens von Komplikationen nach Operationen mit und ohne Drainageneinlage $(p=0,68$; bzw. $\mathrm{p}=0,54)$.

Schlussfolgerung: Unsere Daten deuten an, dass der Verzicht auf eine Drainageneinlage sowohl bei brusterhaltenden Operationen als auch bei Mastektomie nicht zu einer erhöhten Rate von konservativ behandelten Komplikationen und Revisionsoperationen führt. 


\section{Introduction}

\section{$\nabla$}

The surgical therapy of breast cancer has fundamentally changed in the last 20 years. While oncological outcomes have remained the same or even improved, the Halsted radical mastectomy procedure has largely been replaced by breast-conserving surgery combined with radiotherapy. The more general use of neoadjuvant chemotherapy has further reduced the extent of surgery required in patients who respond well to chemotherapy.

The rate of complications following surgery, including nerve damage, infections and skin necrosis [1,2], has also decreased. However, seromas and haematomas still commonly occur postoperatively. This can lead to delayed treatment after surgery, impaired wound healing and longer hospital stays.

Drainage placement was first described by Murphy in 1947 and aimed to reduce these problems [3]. However, evidence for the medical benefit of drain placement after breast surgery is controversial. Some studies have reported wound infections [4-6], increased pain [7,8] and longer hospital stays [8-11] as a consequence of drainage placement during breast surgery.

In the past, various attempts were proposed to reduce the formation of seromas. The methods used ranged from simple compression bandages [12], the use of special surgical instruments [13], the injection of sclerosing agents [14] to wound closure with fibrin glue [15] and physiotherapy [16]. The published data on the benefits of these respective methods are, however, contradictory. Several review articles came to the conclusion that a clinical benefit in the form of reduced seroma formation rates after breast surgery could not be demonstrated for any of these methods with sufficient statistical confidence $[5,17,18]$.

The removal of drains is usually possible without any problems in the first few days postoperatively if the amount of drained fluid is low [11]. The question therefore arises whether, given the latest surgical techniques, using a Redon drain in breast surgery still effects the rates of revision and of conservatively treated complications (secondary bleeding or seroma) or whether it would be possible to dispense with drain placement if there are no additional risk factors.

\section{Materials and Method}

A retrospective analysis of patients operated on in the Hohenlohe Breast Centre in the period from January 2009 to April 2012 included datasets of 678 patients with a diagnosis of breast cancer or ductal carcinoma in situ (DCIS). Data were collected from the tumour database of the certified breast centre, surgery reports, medical charts and discharge letters. A total of 105 out of 678 patients were excluded from further analysis for any one of the following reasons ( Fig. 1): all patients classified as "secondary carcinoma", with bilateral breast cancer, with recurrence, with metastases or with an unknown primary tumour were excluded from statistical analysis as well as patients who had started neoadjuvant chemotherapy or hormone therapy or who had had surgery outside the survey period. Some patients rejected surgical treatment or preferred to undergo further treatment in another hospital. Two patients died during the time of treatment planning from causes unrelated to cancer.

The remaining 573 patients were operated on by any one of 7 experienced breast surgeons (number of operations $n_{1 / 2 / 3 / 4 / 5 / 6 /}$ $7=25 / 26 / 44 / 45 / 123 / 152 / 158)$. Approval for the study was applied for and received from the appropriate Ethics Committee

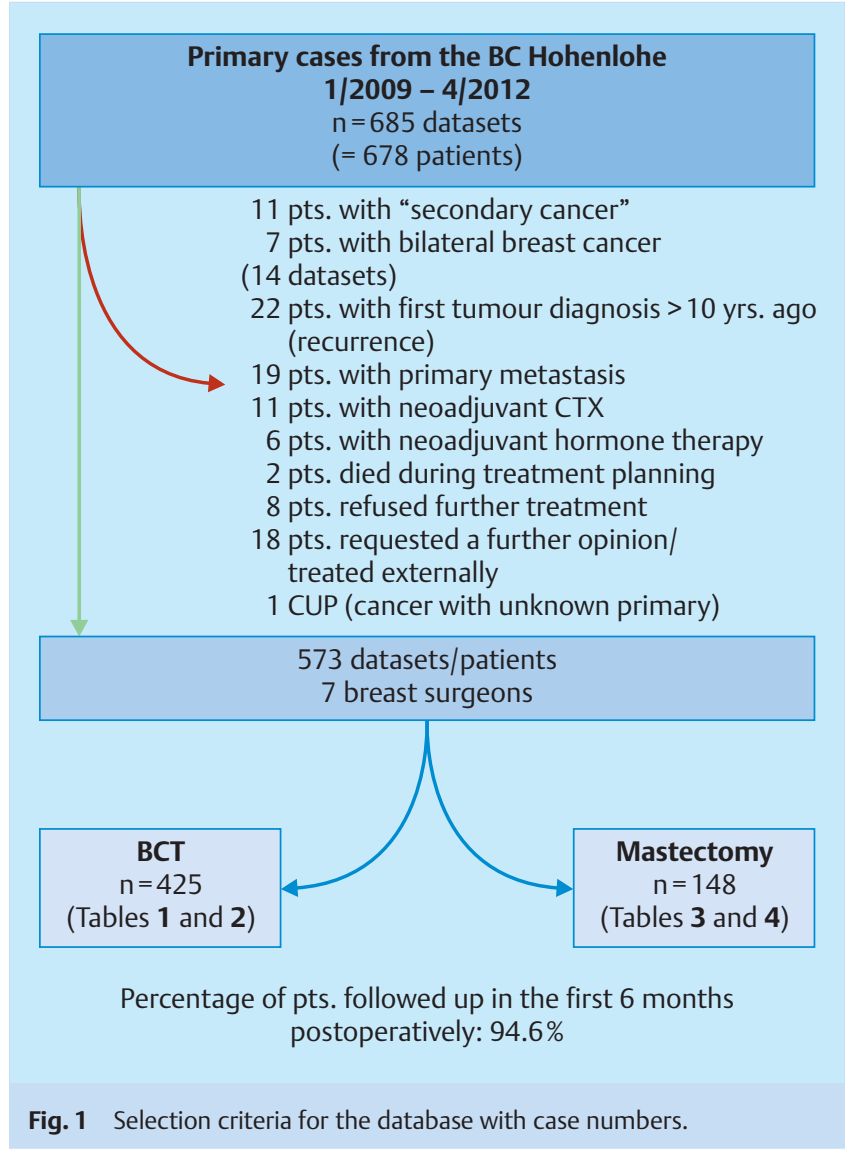

(Approval number S-509/2011). Patients were informed preoperatively about the procedure.

If breast-conserving tumorectomy was not possible because of tumour size, the patient was offered neoadjuvant chemotherapy or two-stage reconstruction after breast ablation. The standard surgery protocol allowed the use of scalpels, scissors and bipolar forceps as standard instruments for haemostasis. Monopolar instruments or argon-ion lasers were used in individual cases. The surgeon decided on the type of incision based on considerations of oncological safety and cosmesis.

Patients were given one intraoperative dose of antibiotics (cefazolin 2 g i.v.); haemostatic agents (e.g. Arista ${ }^{\circledR}$, Floseal ${ }^{\circledR}$, Tabo$\operatorname{tamp}^{\circledR}$ ) were not used. Postoperatively, all patients were treated with a circular compression bandage which was removed on the 1st postoperative day.

In breast-conserving therapy (BCT) the preferred approach was tumorectomy with resection of the skin and fascia. Coverage of the defect was done by subcutaneous mobilisation of breast glands in adjacent quadrants. Rotationplasty or reconstruction (free or pedicled flaps, B-plasty) were not done. If drains were used, a suction drain was placed in each separate wound (tumour bed and axilla).

The surgical technique used in mastectomy procedures included resection of the mammary gland with removal of the nipple and the pectoral fascia. Lymph node dissection was done from the lateral resection border. Drainage of fluids was done through the chest wall.

Removal of sentinel lymph nodes was done through an incision with a length of around $3 \mathrm{~cm}$ directly over the area with the highest count subsequent to marking with technetium-99 and meth- 
ylene blue. For axillary dissection the incision was extended accordingly.

In the period to April 2012, no drains were placed in 143 patients who had surgery with limited blood loss. Only the primary intervention was included in the analysis; subsequent interventions were not taken into account.

A total of 443 patients (77.3\%) underwent additional treatment after surgical therapy in our breast centre. Of the remaining 130 patients, 103 patients (18.0\%) had a documented follow-up examination by their general practitioner or gynaecologist. In such cases, the breast centre annually contacts all registered doctors caring for former patients of the breast centre, asking the physicians about the patient's performance status (ECOG status), the findings at examination and any complications.

No information was available for 27 patients. Of these patients, 2 patients $(0.3 \%)$ did not wish any data to be passed on to the centre, while no further information about performance status or follow-up care was available for the remaining 25 patients (4.4\%).

Overall, this corresponds to a follow-up rate of $95.3 \%$ in the 1 st half year after diagnosis. Postoperative complications such as haematomas, wound infections, seroma formation or seroma puncture were recorded immediately postoperatively or the information obtained from the gynaecologist or physician responsible for follow-up care or recorded at follow-up examinations. In addition, the wound was examined prior to initiating drug treatment or radiotherapy. For patients with clinically relevant complaints or functional impairments due to seroma formation, we followed the recommendations of previous studies $[9,19]$ and carried out ultrasound-guided seroma aspiration. Clinically occult seromas or haematomas were followed up and punctured if they became symptomatic.

All statistical analysis was done using SPSS (Version 19; IBM Corporation, New York, USA). Data are represented using descriptive baseline comparisons of all investigated variables with empirical measures of central tendency and measures of dispersion. Depending on the scale of measurement, data are shown using mean values and standard deviation, median values and range or frequency. Statistical comparisons between patient groups with and without drains were done with Fisher's test or $\mathrm{X}^{2}$-test (for frequency data), t-tests (for normally distributed metric data) or Mann-Whitney U-test (for non-normally distributed metrical data). Adjustment of significance level for multiple tests (Bonferroni correction) was done for statistical comparisons between patient groups.

\section{Results}

$\nabla$

Of the 573 patients, 425 (74.2\%) cases underwent breast-conserving therapy (BCT) at initial surgery. A total of 148 (25.8\%) patients had primary mastectomy. After all surgical interventions were completed, the rate of breast-conserving surgeries was $407 / 573$ or $71.0 \%$.

Patients with primary mastectomy were significantly older (BCT: $60.3 \pm 11.5$ years; mastectomy $67.8 \pm 14.2$ years; $t$-test: $t=5.82$; $\mathrm{p}<0.001$ ), and tumours in patients with primary mastectomy were significantly larger (pT3, pT4) compared to patients with primary breast-conserving surgery $\left(X^{2}\right.$-test: $X^{2}=137.3$; $\mathrm{p}<0.001)$. Patients with primary mastectomy also had tumours with less differentiated cells (grade 3 ) significantly more often compared to patients with BCT $\left(X^{2}\right.$-test: $\left.X^{2}=18.9 ; p<0.001\right)$.
There was no significant difference between patients with BCT and patients with mastectomy with regard to rates of hormone receptor-positive tumours $\left(X^{2}\right.$-test; $\left.X^{2}=0.2 ; p=0.65\right)$ and HER2/ neu-positive tumours $\left(X^{2}\right.$-test; $\left.X^{2}=3.3 ; p=0.07\right)$. A second resection had to be carried out in 123 patients $(23.0 \%)$ due to pathological findings ( $\mathrm{R} 1$ or too small safety margins). The proportion of patients requiring a second resection did not differ significantly between patients with BCT and patients with mastectomy (BCT: 24.7\%; mastectomy: $18.2 \%$; $\mathrm{X}^{2}$-test: $\mathrm{X}^{2}=2.59 ; \mathrm{p}=0.11$ ).

A total of 77 (13.4\%) patients had neither sentinel lymph node biopsy (SNB) nor axillary lymph node dissection (ALND). All of these were either patients with DCIS or elderly patients (75+ years), for whom the comorbidity associated with axillary surgery was weighed against the potential oncological benefit and considered too high. The proportion of these patients in each group did not differ significantly between the group with BCT and the group with mastectomy $\left(X^{2}\right.$-test: $\left.X^{2}=0.10 ; p=0.76\right)$.

Patients with BCT had SNB without subsequent ALND significantly more often compared to patients with mastectomy (BCT: 58.1\%; mastectomy: $34.5 \%$; $X^{2}$-test: $X^{2}=24.62$; $<<0.001$ ), while conversely, patients with mastectomy underwent ALND significantly more often than patients with BCT (mastectomy: $51.4 \%$; BCT: $28.7 \%$; $X^{2}$-test: $\left.X^{2}=24.89 ; p<0.001\right)$. Clinically asymptomatic seromas were treated conservatively. Symptomatic seromas and seromas causing functional impairment were treated using puncture. One patient who had breast-conserving surgery without drainage required treatment for seroma for a period after discharge. A second operation was necessary in 23 cases due to complications such as haematomas or infections. The proportion of patients who had revision surgery was significantly higher in the group of patients with mastectomy compared to the group of patients with BCT (Mastectomy: 6.8\%; BCT: 3.1\%; $\mathrm{X}^{2}$-test: $\mathrm{X}^{2}=3.9 ; \mathrm{p}=0.048$ ). For this reason, patients with BCT and patients with mastectomy will be examined and analysed separately below.

\section{Patients with breast-conserving surgery}

No drains were placed in 110 patients (25.9\%) out of a total of 425 patients undergoing breast-conserving primary intervention. A statistical comparison of the tumour characteristics and surgical data for BCT patients with and without placement of drains showed - with one exception - no significant differences between groups after adjusting the level of significance for multiple tests (cf. $\bigcirc$ Tables 1 and 2 ). The exception was those patients who were HER2/neu positive; the proportion of HER2/neu-positive patients was significantly higher in the group with placement of drains compared to the group without drains ( $X^{2}$-test: $X^{2}=10.0$; $\mathrm{p}=0.002)$. If only BCT patients who had revision surgery $(\mathrm{n}=13)$ were evaluated, then there were no significant differences with regard to tumour characteristics and surgical data between the group without drains and the group with drains (all $\mathrm{p}>0.05$ ). However, the limited number of cases means that these results should be interpreted with care (no statistical tests could be performed for some of the variables due to the limited case numbers). There was no significant difference with regard to the incidence of revision surgery for complications between the group without drains (3.6\%, 4 of 110 patients) and the group with drains (2.9\%, 9 of 315 patients; $X^{2}$-test: $X^{2}=0.17, p=0.68$; cf. also - Table 2). 
Table 1 Patient and tumour characteristics of patients with breast-conserving surgery $(n=425)$.

\begin{tabular}{|c|c|c|c|c|}
\hline & & \multicolumn{3}{|c|}{ Patients with breast-conserving surgery $(n=425)$} \\
\hline & & No drains $(n=110)$ & Drain placement $(n=315)$ & p-value \\
\hline \multirow[t]{2}{*}{ Age } & Mean & 59.1 & 60.7 & $0.19^{1}$ \\
\hline & SD & 11.2 & 11.6 & \\
\hline \multirow[t]{6}{*}{ Tumour size } & pTis & $11(10.0 \%)$ & $36(11.4 \%)$ & $0.12^{2}$ \\
\hline & pT1 & $57(51.8 \%)$ & $186(59.0 \%)$ & \\
\hline & PT2 & $37(33.6 \%)$ & $84(26.7 \%)$ & \\
\hline & pT3 & $0(0.0 \%)$ & $2(0.6 \%)$ & \\
\hline & pT4 & $2(1.8 \%)$ & $0(0.0 \%)$ & \\
\hline & pTX+ypT0 & $3(2.7 \%)$ & $7(2.2 \%)$ & \\
\hline \multirow[t]{3}{*}{ Hormone receptor status } & positive & $94(85.5 \%)$ & $252(80.0 \%)$ & $0.07^{2}$ \\
\hline & negative & $12(10.9 \%)$ & $59(18.7 \%)$ & \\
\hline & unknown & $4(3.6 \%)$ & $4(1.3 \%)$ & \\
\hline \multirow[t]{3}{*}{ HER2/neu status } & positive & $20(18.2 \%)$ & $101(32.1 \%)$ & $0.002^{2 *}$ \\
\hline & negative & 85 (77.3\%) & $181(57.5 \%)$ & \\
\hline & unknown & $5(4.5 \%)$ & $33(10.5 \%)$ & \\
\hline \multirow[t]{4}{*}{ Grade } & G1 & $13(11.8 \%)$ & $39(12.4 \%)$ & $0.16^{2}$ \\
\hline & G2 & $69(62.7 \%)$ & $165(52.4 \%)$ & \\
\hline & G3 & $27(24.5 \%)$ & $99(31.4 \%)$ & \\
\hline & GX & $1(0.9 \%)$ & $12(3.8 \%)$ & \\
\hline \multirow[t]{2}{*}{ Cancer location (side) } & right & 57 & 156 & $0.68^{2}$ \\
\hline & left & 53 & 159 & \\
\hline
\end{tabular}

SD: standard deviation

1 t-test

${ }^{2} \mathrm{X}^{2}$-test

* significant after Bonferroni correction to adjust the significance level for multiple tests

Table 2 Surgical data and complication rates for patients with breast-conserving surgery $(n=425)$.

\begin{tabular}{|c|c|c|c|}
\hline & \multicolumn{3}{|c|}{ Patients with breast-conserving surgery $(n=425)$} \\
\hline & No drains $(n=110)$ & Drain placement $(n=315)$ & p-value \\
\hline No LN removed & $15(13.6 \%)$ & $41(13.0 \%)$ & $0.87^{1}$ \\
\hline SNB (no ALND) & $64(58.2 \%)$ & $183(58.1 \%)$ & $0.99^{1}$ \\
\hline Number of LN removed (mean, range) & $1,0-7$ & $2,1-13$ & $0.013^{2}$ \\
\hline ALND & $31(28.2 \%)$ & $91(28.9 \%)$ & $0.89^{1}$ \\
\hline Number of LN removed (mean, range) & $12,1-20$ & $14,1-37$ & $0.07^{2}$ \\
\hline Resection margin in mm (mean \pm SD) & $4.7 \pm 3.0$ & $5.3 \pm 3.9$ & $0.16^{3}$ \\
\hline Second resection & $29(26.4 \%)$ & $76(24.1 \%)$ & $0.64^{1}$ \\
\hline Revision surgery (due to complications) & $4(3.6 \%)$ & $9(2.9 \%)$ & $0.68^{1}$ \\
\hline
\end{tabular}

LN: lymph nodes; SNB: sentinel lymph node biopsy; ALND: axillary lymph node dissection; SD: standard deviation

${ }^{1} \mathrm{X}^{2}$-test

${ }^{2}$ Mann-Whitney U-test

${ }^{3}$ t-test

\section{Patients with mastectomy}

Out of a total of 148 patients with mastectomy, no drain placement was done in 33 patients (22.3\%). A statistical comparison of tumour characteristics and surgical data showed no significant difference between mastectomy patients with drains and mastectomy patients without drains after adjusting the significance level for multiple tests (cf. $\bigcirc$ Tables 3 and 4). In the group of mastectomy patients who required revision surgery $(n=10)$, there were no significant differences with regard to tumour characteristics and surgical data between the group with drains and the group without drains (all p >0.05). As was noted for the comparison of BCT patients requiring revision surgery, the limited number of cases means that the results must be interpreted with care (here too, no statistical tests could be done for some of the variables due to the limited case numbers). As was reported above for $\mathrm{BCT}$ patients, there was no significant differ- ence in the incidence of revision surgery for complications in the group of mastectomy patients between the group without drains (9.1\%; 3 of 33 patients) and the group with drain placement (6.1\%, 7 of 115 patients; $X^{2}$-test: $X^{2}=0.37, p=0.54$; $c$. - Table 4).

\section{Discussion}

This retrospective study investigated whether the placement of Redon drains is necessary during primary surgery for breast cancer or its precursors. The results of our study showed that in our cohort non-placement of a drain was not associated with a higher rate of revision, neither in the group who had breast-conserving surgery nor in the group with mastectomy; the overall rate of revision was very low at $4 \%$ (23 out of 573 cases) [20]. 
Table 3 Patient and tumour characteristics of patients with mastectomy $(n=148)$.

\begin{tabular}{|c|c|c|c|c|}
\hline & & \multicolumn{3}{|c|}{ Patients with mastectomy $(n=148)$} \\
\hline & & No drains $(n=33)$ & Drain placement $(n=115)$ & p-value \\
\hline \multirow[t]{2}{*}{ Age } & Mean & 65.3 & 68.5 & $0.25^{1}$ \\
\hline & SD & 14.6 & 14.0 & \\
\hline \multirow[t]{6}{*}{ Tumour size } & pTis & $3(9.1 \%)$ & $2(1.7 \%)$ & $0.03^{2}$ \\
\hline & pT1 & $4(12.1 \%)$ & $23(20.0 \%)$ & \\
\hline & PT2 & $15(45.5 \%)$ & $71(61.7 \%)$ & \\
\hline & PT3 & $7(21.2 \%)$ & $12(10.4 \%)$ & \\
\hline & pT4 & $3(9.1 \%)$ & $7(6.1 \%)$ & \\
\hline & рTX+урТ0 & $1(3.0 \%)$ & $0(0.0 \%)$ & \\
\hline \multirow[t]{3}{*}{ Hormone receptor status } & positive & $27(81.8 \%)$ & $91(79.1 \%)$ & $0.56^{2}$ \\
\hline & negative & $5(15.2 \%)$ & $23(20.0 \%)$ & \\
\hline & unknown & $1(3.0 \%)$ & $1(0.9 \%)$ & \\
\hline \multirow[t]{3}{*}{ HER2/neu status } & positive & $8(24.2 \%)$ & $46(40.0 \%)$ & $0.24^{2}$ \\
\hline & negative & $20(60.6 \%)$ & $67(58.3 \%)$ & \\
\hline & unknown & $5(15.2 \%)$ & $2(1.7 \%)$ & \\
\hline \multirow[t]{4}{*}{ Grade } & G1 & $0(0.0 \%)$ & $3(2.6 \%)$ & $0.15^{2}$ \\
\hline & G2 & $16(48.5 \%)$ & $67(58.3 \%)$ & \\
\hline & G3 & $16(48.5 \%)$ & $45(39.1 \%)$ & \\
\hline & $G X$ & $1(3.0 \%)$ & $0(0.0 \%)$ & \\
\hline \multirow[t]{2}{*}{ Tumour location (side) } & right & 15 & 60 & $0.50^{2}$ \\
\hline & left & 18 & 55 & \\
\hline
\end{tabular}

Table 4 Surgical data and complication rates for patients with mastectomy $(n=148)$.

\begin{tabular}{|c|c|c|c|}
\hline & \multicolumn{3}{|c|}{ Patients with mastectomy $(n=148)$} \\
\hline & No drains $(n=33$ ) & Drain placement $(n=115)$ & p-value \\
\hline No LN removed & $8(24.2 \%)$ & $13(11.3 \%)$ & $0.06^{1}$ \\
\hline SNB (no ALND) & $11(33.3 \%)$ & $40(34.8 \%)$ & $0.88^{1}$ \\
\hline Number of LN removed (mean, range) & $2,1-7$ & $2,1-5$ & $0.87^{2}$ \\
\hline ALND & $14(42.4 \%)$ & $62(53.9 \%)$ & $0.24^{1}$ \\
\hline Number of LN removed (mean, range) & $13,6-26$ & $13.5,1-27$ & $0.50^{2}$ \\
\hline Resection margin in $\mathrm{mm}$ (mean $\pm \mathrm{SD}$ ) & $7.9 \pm 8.5$ & $7.0 \pm 5.3$ & $0.49^{3}$ \\
\hline Second resection & $6(18.2 \%)$ & $21(18.3 \%)$ & $0.99^{1}$ \\
\hline Revision surgery (due to complications) & $3(9.1 \%)$ & $7(6.1 \%)$ & $0.54^{1}$ \\
\hline
\end{tabular}

LN: lymph nodes; SNB: sentinel lymph node biopsy; ALND: axillary lymph node dissection; SD: standard deviation

${ }^{1} \mathrm{X}^{2}$-test

${ }^{2}$ Mann-Whitney U-test

3 t-test

Our study differed from prospective studies on this topic $[5,11$, $21,22]$, as the basic population selected for the cohort study consisted of patients treated in the breast centre with a primary diagnosis of breast cancer. This means that our study covered a wide range of different oncological treatment options, which also resulted in a higher number of cases compared to other studies. The disadvantage of this retrospective unicentral data mining is the lack of any preoperative randomisation. The final investigations were done within the Department, but not all complications were potentially known at the time of discharge. Prior to any radiotherapy or chemotherapy, patients underwent a further physical examination with investigation of their medical history. If the patients did not undergo any treatment after surgery, it was up to the discretion of the physician providing follow-up care whether to discuss any existing complaints with the patient. De- spite comparable tumour characteristics, it was not possible to exclude surgeon's bias.

\section{Secondary bleeding}

Haematomas are well known complications which can delay wound healing. Depending on their size and the clinical findings, haematomas can be treated conservatively. Nevertheless, haematomas occurring in the immediate postoperative period due to acute secondary bleeding were the most common reason for revision surgery in our study.

The number of cases with secondary bleeding can be reduced by a careful and thorough coagulation of vessels. However, electrocoagulation has been reported to be a risk factor for postoperative seroma formation [12]. Achieving maximum haemostasis with minimum coagulation therefore depends on the surgeon's experience. Moreover, the placement of drains can result in the 
formation of fewer postoperative haematomas requiring revision surgery. A drain together with a compression dressing should ensure drainage of haematomas or seromas in the wound site. Compression bandages should also stop minimal secondary bleeding. Clinical experience, however, shows that this rarely occurs as the formation of coagulum in the drainage tube during secondary bleeding can plug the drainage early on. This can lead to haematoma formation in the wound bed which presents as a firm, elastic, partly painful mass at the operative site. In many cases, these acute haematomas have to be removed surgically to provide relief or achieve haemostasis. There are still insufficient studies in the literature on the impact of well-placed compression dressings, the number of drains and different suction strengths on secondary bleeding and haematomas $[12,23,24]$.

\section{Seroma formation}

After acute haematoma, the postoperative formation of overlarge or infected seromas is a complication which occasionally requires surgical intervention. Seroma formation is caused by impaired or missing lymphatic vessels and postoperative inflammatory reactions. Use of the sentinel lymph node technique contributes to preserving lymphatic drainage in the majority of cases. Studies have shown that use of SLNB reduced the incidence of lymphedema $[2,25,26]$.

To reduce seroma formation, different surgical techniques and instruments have been evaluated for their impact on postoperative seroma formation $[10,17,27,28]$. In a recent review, however, Srivastava and colleagues [5] showed that the results of existing studies on this topic are contradictory. To date, there is no convincing and unambiguous data available proving the efficacy of the different surgical techniques and instruments for the reduction of seroma formation.

The intraoperative use of fibrin glue to prevent the formation of seromas postoperatively has also been studied. Particularly interesting in this context was the prospective randomised study by Jain et al. [8], in which the efficacy of drain placement was compared with the efficacy of fibrin sealant in 116 patients with BCT/ mastectomy and level I \& II lymphadenectomy. The study came to the conclusion that the placement of drains did not prevent the formation of seromas and resulted in a longer postoperative hospital stay ( 2.9 vs. 1.9 days; $\mathrm{p}<0.001$ ) and increased pain at 24 hours (pain score 4.5 vs. 3.2; $\mathrm{p}<0.001$ ) and 48 hours postoperatively (pain score 2.2 vs. $1.4 ; \mathrm{p}=0.002$ ). In patients with mastectomy, it was found that fibrin glue significantly reduced the incidence and total volume of seromas. The authors recommended dispensing with the drains and using fibrin sealants, even in mastectomy procedures. The rate of revision reported by Jain et al. was $0 \%$, although 3 patients received oral antibiotics and 1 patient was treated for haematoma on an outpatient basis. Nevertheless, the efficacy of fibrin sealant to reduce seroma formation remains controversial, and a recent meta-analysis [18] showed no significant impact of fibrin glue on the incidence of seroma formation, total seroma volume, wound infection and length of hospital stay.

Purushotham et al. [9] compared length of hospital stay and psychological and physical morbidity for patients with primary breast cancer treated either by conventional surgery with drain placement or surgically without placement of drains (adaptation using remaining tissue/subcutaneous tissue/pectoral fascia). In their study, non-placement of drains resulted in a significant decrease in the length of hospital stay, while the level of patient sat- isfaction and the incidence of seromas und wound infections did not differ between groups.

In contrast, in a meta-analysis of 6 randomised studies published in 2009 by Droeser and colleagues [11], they found that volumecontrolled placement of drains after breast surgery with axillary lymph node dissection reduced the formation of clinically symptomatic seromas and the number of seroma punctures compared to non-placement or only brief placement of drains. There was no difference in the rate of infections. The investigated studies only included patients who had axillary dissection and the majority patients had undergone mastectomy. He et al. [22] confirmed these results in a recent review article where the patient cohort was surgically heterogeneous. But both authors recommended further prospective studies to assess the necessity for drain placement in breast surgery with axillary lymph node dissection. The results of a large prospective study with 596 patients were recently published by Taylor et al. [29]. No difference in the incidence of seromas, the number of seroma punctures and wound infection rates was found between patients with drains and patients without drain placement, irrespective of the type of surgery. This data agrees with the results of our retrospective study, which investigated a similar number of patients, although it should be noted that in our study the proportion of patients who had breast-conserving surgery was considerably higher compared to the study by Taylor et al.

\section{Wound infections}

Postoperative infections are yet another type of complication; wound infections are usually treated conservatively and only occasionally require revision surgery.

Internationally, the reported rate of infection after breast surgery ranges between 0.8 and $26 \%[30,31]$. OnkoZert has proposed that the rate of infections in certified breast centres should not exceed $5 \%$ [32]. Our data complies with this proposal, and no postoperative infections which led to a delay in subsequent treatment or hospitalisation of the patient occurred during the period under investigation.

In a systematic review by Xue et al. [4], postoperative drains, longer drainage periods and the placement of a secondary drain were identified as risk factors for postoperative wound infection. In contrast, Droeser et al. [11] and He et al. [22] found no association between drain placement and wound infection in their reviews.

\section{Additional risk factors for complications after breast surgery}

A body mass index $(\mathrm{BMI})>30$ is a well-known risk factor for impaired wound healing after abdominal surgery [33]. Similarly, a 12-fold higher risk of complications has been reported for elective breast surgery in women with higher BMI [34], although the majority of cases (80\%) in this study had reduction surgery. Helyer et al. also described an association between obesity and lymphedema [35]. In addition to BMI, the study by Helyer and colleagues also identified the number of resected lymph nodes as a risk factor for the development of postoperative lymphedema. In our study, both the percentage of patients undergoing ALND and the numbers of lymph nodes resected at ALND were comparable for both groups (cf. $\odot$ Tables 2 and 4). Only in the group of mastectomy patients requiring revision surgery for complications did patients with drains have ALND more often than patients without drain placement. The average number of 
resected lymph nodes was also slightly higher in the group with complications compared to the remaining patients.

In addition to BMI [34], tumour size [13] and the relation between surgical specimen volume and breast size could also have an impact. As no data on the size and weight of the resected specimen or chest circumference/cup size was collected, these variables were not included in our analysis.

\section{Conclusion}

$\nabla$

Our data shows that in our cohort non-placement of drains had no effect on the rate of surgical revisions due to complications, neither in the group with breast-conserving surgery nor in the group with mastectomy. As a review of the literature found no arguments either for or against the standard placement of drains, we would recommend an individualised approach adapted to the individual risk.

\section{Conflict of Interest}

$\nabla$

The authors declare that they have no financial relationship with any company with an interest in the subject matter relevant for this article.

\section{References}

1 Kuroi K, Shimozuma K, Taguchi T et al. Evidence-based risk factors for seroma formation in breast surgery. Jpn J Clin Oncol 2006; 36: 197206

2 Golshan M, Martin WJ, Dowlatshahi K. Sentinel lymph node biopsy lowers the rate of lymphedema when compared with standard axillary lymph node dissection. Am Surgeon 2003; 69: 209-211; discussion 212

3 Moss JP. Historical and current perspectives on surgical drainage. Surg Gynecol Obstet 1981; 152: 517-527

4 Xue DQ Qian C, Yang $L$ et al. Risk factors for surgical site infections after breast surgery: a systematic review and meta-analysis. Eur J Surg Oncol 2012; 38: 375-381

5 Srivastava V, Basu S, Shukla VK. Seroma formation after breast cancer surgery: what we have learned in the last two decades. J Breast Cancer 2012; 15: 373-380

6 Baas-Vrancken Peeters MJ, Kluit AB, Merkus JW et al. Short versus longterm postoperative drainage of the axilla after axillary lymph node dissection. A prospective randomized study. Breast Cancer Res Treat 2005; 93: 271-275

7 Zavotsky J, Jones RC, Brennan MB et al. Evaluation of axillary lymphadenectomy without axillary drainage for patients undergoing breastconserving therapy. Ann Surg Oncol 1998; 5: 227-231

8 Jain PK, Sowdi R, Anderson AD et al. Randomized clinical trial investigating the use of drains and fibrin sealant following surgery for breast cancer. Br J Surg 2004; 91: 54-60

9 Purushotham AD, McLatchie E, Young D et al. Randomized clinical trial of no wound drains and early discharge in the treatment of women with breast cancer. Br J Surg 2002; 89: 286-292

10 Classe JM, Berchery D, Campion L et al. Randomized clinical trial comparing axillary padding with closed suction drainage for the axillary wound after lymphadenectomy for breast cancer. Br J Surg 2006; 93: 820-824

11 Droeser RA, Frey DM, Oertli D et al. Volume-controlled vs. no/shortterm drainage after axillary lymph node dissection in breast cancer surgery: a meta-analysis. Breast 2009; 18: 109-114

12 O'Hea BJ, Ho MN, Petrek JA. External compression dressing versus standard dressing after axillary lymphadenectomy. Am J Surg 1999; 177: 450-453
13 Lumachi F, Brandes AA, Burelli P et al. Seroma prevention following axillary dissection in patients with breast cancer by using ultrasound scissors: a prospective clinical study. Eur J Surg Oncol 2004; 30: 526530

14 McCarthy PM, Martin JK, Wells DC et al. An aborted, prospective, randomized trial of sclerotherapy for prolonged drainage after mastectomy. Surg Gynecol Obstet 1986; 162: 418-420

15 Ulusoy AN, Polat C, Alvur M et al. Effect of fibrin glue on lymphatic drainage and on drain removal time after modified radical mastectomy: a prospective randomized study. Breast J 2003; 9: 393-396

16 Shamley DR, Barker K, Simonite Vet al. Delayed versus immediate exercises following surgery for breast cancer: a systematic review. Breast Cancer Res Treat 2005; 90: 263-271

17 Agrawal A, Ayantunde AA, Cheung KL. Concepts of seroma formation and prevention in breast cancer surgery. ANZ J Surg 2006; 76: 10881095

18 Sajid MS, Hutson K, Kalra $L$ et al. The role of fibrin glue instillation under skin flaps in the prevention of seroma formation and related morbidities following breast and axillary surgery for breast cancer: a meta-analysis. J Surg Oncol 2012; 106: 783-795

19 Andeweg CS, Schriek MJ, Heisterkamp J et al. Seroma formation in two cohorts after axillary lymph node dissection in breast cancer surgery: does timing of drain removal matter? Breast J 2011; 17: 359-364

20 Dieterich M, Dieterich $H$, Moch $H$ et al. Re-excision rates and local recurrence in breast cancer patients undergoing breast conserving therapy. Geburtsh Frauenheilk 2012; 72: 1018-1023

21 van Bemmel AJ, van de Velde CJ, Schmitz RF et al. Prevention of seroma formation after axillary dissection in breast cancer: a systematic review. Eur J Surg Oncol 2011; 37: 829-835

22 He XD, Guo ZH, Tian JH et al. Whether drainage should be used after surgery for breast cancer? A systematic review of randomized controlled trials. Med Oncol 2011; 28 (Suppl. 1): S22-S30

23 van Heurn LW, Brink PR. Prospective randomized trial of high versus low vacuum drainage after axillary lymphadenectomy. Br J Surg 1995; 82: 931-932

24 Petrek JA, Peters MM, Cirrincione Cet al. A prospective randomized trial of single versus multiple drains in the axilla after lymphadenectomy. Surg Gynecol Obstet 1992; 175: 405-409

25 Crane-Okada $R$, Wascher RA, Elashoff $D$ et al. Long-term morbidity of sentinel node biopsy versus complete axillary dissection for unilateral breast cancer. Ann Surg Oncol 2008; 15: 1996-2005

26 Sakorafas GH, Peros G, Cataliotti L et al. Lymphedema following axillary lymph node dissection for breast cancer. Surg Oncol 2006; 15: 153165

27 Woodworth PA, McBoyle MF, Helmer SD et al. Seroma formation after breast cancer surgery: incidence and predicting factors. Am Surg 2000; 66: 444-450; discussion 450-451

28 Kühn T, Santjohanser C, Koretz K et al. [Endoscopic axillary lymph node excision-results of a pilot study]. Zentralbl Gynakol 1999; 121: 82-87

29 Taylor JC, Rai S, Hoar $F$ et al. Breast cancer surgery without suction drainage: The impact of adopting a 'no drains' policy on symptomatic seroma formation rates. Eur J Surg Oncol 2013; 39: 334-338

30 Bunn F, Jones DJ, Bell-Syer S. Prophylactic antibiotics to prevent surgical site infection after breast cancer surgery. Cochrane Database Syst Rev 2012; 1: CD005360

31 Degnim AC, Throckmorton AD, Boostrom SY et al. Surgical site infection after breast surgery: impact of 2010 CDC reporting guidelines. Ann Surg Oncol 2012; 19: 4099-4103

32 OnkoZert. Erhebungsbogen für Brustzentren von der DKG und Deutschen Gesellschaft für Senologie. 2012. Online: www.oncocert.de

33 Mitas L, Rogulski L, Ziebinski J. Does obesity complicate perioperative course in patients undergoing abdominal hysterectomy? Arch Gynecol Obstet 2012; 286: 385-388

34 Chen $C L$, Shore $A D$, Johns $R$ et al. The impact of obesity on breast surgery complications. Plast Reconstr Surg 2011; 128: 395e-402e

35 Helyer $L K$, Varnic $M$, Le $L W$ et al. Obesity is a risk factor for developing postoperative lymphedema in breast cancer patients. Breast J 2010; 16: $48-54$ 